\title{
Avaliação da Inclusão Digital de Deficientes Visuais por meio do Software Dos Vox
}

\section{Maria da Luz Oliveira Diass, James da Luz Dias ${ }^{1}$, Kércia Maria Clementino Santos ${ }^{1}$, José Antônio dos Santos Borges ${ }^{2}$}

\author{
${ }^{1}$ Instituto de Federal de Educação, Ciência e Tecnologia do Piauí (IFPI) \\ Av. Pedro Freitas, 1020, Vermelha - 64.018-000- Teresina - PI - Brasil \\ ${ }^{3}$ Departamento de Computação \\ Universidade Federal do Rio de Janeiro (UFRJ) - Rio de Janeiro - Brazil \\ \{jamesdias0, darluzoliveira\}@gmail.com, wkala@bol.com, \\ antonio2@nce.ufrj.br
}

\begin{abstract}
The present article aims to present the project developed with ten Visual Deficients $(D V s)$ resident in Teresina and circumambient local authorities, in which they had the opportunity for manipulating the system DosVox. The software is considered one when of they were most used by the DVs, since it makes possible the straight contact of the blind user with the computer. While making the project real, the pupils were suitable carrying out several activities in the computer through the software. Long the benefits of the program present the community in general to the DVs, as well as to spread the results of the executed project, waking in the persons the wish of knowing the tool and like her it is helping the DVs they have quality of life, with help of the technologies

Resumo. O presente artigo visa apresentar o projeto desenvolvido com dez Deficientes Visuais (DVs) residentes em Teresina e municipios circunvizinhos, no qual tiveram a oportunidade de manipular o sistema DosVox. O software é considerado um dos mais utilizados pelos DVs, pois possibilita o contato direto do usuário cego com o computador. Ao concretizar o projeto, os alunos estavam aptos a realizar diversas atividades no computador por meio do software. Almeja-se apresentar a comunidade em geral os beneficios do programa aos $D V s$, bem como divulgar os resultados do projeto executado, despertando nas pessoas o desejo de conhecer a ferramenta e como ela vem ajudando os DVs terem qualidade de vida, com auxílio das tecnologias.
\end{abstract}

\section{Introdução}

A utilização de recursos tecnológicos atualmente é muito comum em diversos contextos, nas fábricas, empresas de pequeno, médio e grande porte e principalmente na vida pessoal de cada indivíduo. Como a tecnologia se faz presente na vida de todas as pessoas, seja ela com ou sem deficiência, desperta-se o desejo de analisar como a tecnologia pode beneficiar as Pessoas com Necessidades Educacionais Especiais (PNEEs), especificamente os Deficientes Visuais (DVs). O presente trabalho deu continuidade ao Projeto "Inclusão por meio do DosVox", essa etapa se propõe avaliar o Software DosVox e sua utilização por pessoas cegas, para poder se entender como essa ferramenta tecnológica pode funcionar como elemento facilitador no processo de inclusão digital das pessoas com DV, mediante a avaliação da inclusão digital dos DVs que foram contemplados com um projeto sociodigital, realizado durante o segundo semestre de 2014, contemplando 10 (dez) DVs no curso de Noções Básicas de DosVox, que teve uma duração de 52 (cinquenta e duas) horas. 
A forma de avaliação se deu por meio de questionários aplicados aos DVs durante e ao final do curso e pela análise em sala de cada aluno.

A primeira etapa do projeto foi realizada em conjunto com a Ação Social Arquidiocesana (ASA) localizada em Teresina PI, em parceria com o "Projeto Levanta, Vem para o Meio", que trabalha com programas de Reabilitação, Capacitação e Inclusão de pessoas com deficiências no mercado de trabalho. As aulas aconteceram de segunda à sexta no horário de 13:00 às 17:00 horas no laboratório de informática da referida instituição. $\mathrm{O}$ projeto objetivava repassar a manipulação e aprendizagem do sistema operacional DosVox, tendo como foco principal capacitar os alunos com DV residentes em Teresina e municípios circunvizinhos para que utilizassem o DosVox bem como o computador. Esses alunos foram avaliados no laboratório de informática da unidade parceira. O presente artigo apresenta a avaliação do desempenho dos alunos ao utilizar o software DosVox e como essa ferramenta favorece a educação inclusiva.

O projeto desenvolvido apresenta-se comprometido com as descobertas realizadas tanto pelos alunos com DV, quanto pelos idealizadores do projeto, com o intuito de proporcionar melhorias para os DVs. A descoberta por parte dos alunos atendidos se faz necessária para que eles se sintam valorizados e possam usufruir de atividades básicas que o computador pode proporcionar-lhes, fazendo assim um maior uso da informação, uma vez que a mesma é a matéria prima da construção do conhecimento. A informação torna-se o elemento principal na formação de uma sociedade justa e igualitária, fornece uma condição essencial para que as pessoas e instituições estejam aptas a lidar com o novo, a criar e, assim, garantir seu espaço de liberdade e autonomia (TAKAHASHI, 2000, p.45).

Os idealizadores do projeto acreditam que o acesso à informação e aos recursos tecnológicos devem estar disponíveis para todos, e as oportunidades de aprendizagem devem ser concedidas sem nenhuma forma de discriminação. Andrade (2002, p. 1) declara que:

Temos a urgente tarefa da construção de uma sociedade onde haja o respeito à diferenças e as diversidades, com equiparação de direitos e oportunidades, a construção coletiva da sociedade com inclusão social e eliminação de todas as formas e exclusão e segregação.

Pois diversas ações bem mais complexas já foram desenvolvidas no Brasil para os Deficientes Visuais, um com bastante respaldo foi realizado no estado do Paraná. Pansanato et al. (2012) descreve a experiência de inclusão de um estudante cego na educação superior em computação. Ao longo da graduação, os professores tiveram que se preocupar em adaptar e desenvolver, juntamente com um facilitador, mecanismos para facilitar a interpretação de diversos conteúdos da informática que seriam de difícil compreensão para este aluno.

Os resultados deste trabalho poderá se constituir num referencial de suporte para as instituições públicas ou privadas que, preocupadas com a condição dos DVs, optem por direcionar incentivos para projetos similares a este. Essa forma de inclusão por meio da tecnologia digital estimulará outros deficientes visuais a exercer tarefas cotidianas como ler, escrever, digitar e utilizar a Internet como meio de entretenimento e educação, ampliando o grau de conhecimento das tecnologias assistivas de um DV e as oportunidades de inclusão social das PNEEs.

\section{Métodos}

A pesquisa empreendida está alicerçada na abordagem qualitativa e quantitativa, que buscou descrever o processo quanto ao uso do computador pelos deficientes visuais por 
meio do software DosVox. Tais abordagens, segundo Malhotra (2001, p.155), "a pesquisa qualitativa proporciona uma melhor visão e compreensão do contexto do problema, enquanto a pesquisa quantitativa procura quantificar os dados e aplicar alguma forma da análise estatística". O presente trabalho pretende utilizar a pesquisa qualitativa para explicar os resultados obtidos pela pesquisa quantitativa.

Segundo Gil (2002), o levantamento de dados é caracterizado pela interrogação direta das pessoas que farão parte da pesquisa, cujo comportamento se deseja conhecer. Diante disso a técnica de coleta de dados empregada na pesquisa foi a aplicação de questionários durante e após o curso de DosVox. Segundo Cervo \& Bervian (2002, p. 48), o questionário "[...] refere-se a um meio de obter respostas às questões por uma fórmula que o próprio informante preenche". Ele pode conter perguntas abertas e/ou fechadas. As abertas possibilitam respostas mais valiosas e variadas e as fechadas maior facilidade na tabulação e análise dos dados. Portanto, salienta-se que os questionários aplicados possuíam perguntas abertas e fechadas para avaliar a inclusão dos alunos que participaram do curso.

O projeto foi desenvolvido em duas etapas. A primeira foi realizada em conjunto com a Ação Social Arquidiocesana (ASA), em parceria com o "Projeto Levante, Vem para o Meio", que trabalha com programas de Reabilitação, Capacitação e Inclusão de pessoas com deficiências no mercado de trabalho. As aulas aconteceram de segunda a sexta no horário de 13:00 às 17:00 horas no laboratório de informática da instituição parceira. Foram contemplados 10 (dez) DVs, com uma carga horária de 52 (cinquenta e duas) horas. A pesquisa contou com o auxílio de dois alunos do curso de Licenciatura em Informática.

A segunda etapa traz uma avaliação minuciosa da etapa anterior, elencando os pontos positivos e negativos decorrentes do uso do software DosVox pelos alunos contemplados com o projeto, avaliando também a inclusão digital dos alunos.

\section{Resultados e discussões}

A partir da metodologia aplicada foi possível diagnosticar as contribuições que o projeto agregou a cada Deficiente Visual, ou seja, os resultados foram compilados por meio da coleta de dados, utilizando o questionário aplicado aos participantes do projeto e da observação de cada aluno no laboratório de informática.

Todos os alunos contemplados com o projeto disponibilizaram-se a participar da pesquisa, o que leva a crer que a experiência foi satisfatória, pois estes responderam o questionário de forma voluntária. Vale ressaltar que o projeto foi concluído com 07 (sete) DVs, por isso os dados abaixo apresentam-se neste número.

Dos 07 (sete) alunos que participaram da pesquisa, 42,9\% alegaram conheciam o software DosVox só por nome, porém nunca haviam utilizado. O mesmo percentual não conhecia o programa e somente $14 \%$ conhecia. Esta pergunta se fez pertinente uma vez que, segundo Borges (1998), o programa Dosvox vem se desenvolvendo desde 1993 e permanece sendo o sistema mais utilizado no Brasil por deficientes visuais.

Com relação à avaliação do programa, $57,1 \%$ da turma consideraram o mesmo Bom, 28,6\% avaliaram como Ótimo e somente $14,3 \%$ ponderaram o software como Regular. Percebeu-se uma variação em relação à avaliação do software. Uma justificativa dada pelos $14,3 \%$ é que o software necessitaria passar por atualizações, pois os alunos consideravam alguns recursos dificultosos e que necessitariam de melhorias. Vale ressaltar que no dia 23 de Setembro de 2015 o software passou por uma atualização, levando em conta algumas opiniões dos usuários do DosVox. 
V Congresso Brasileiro de Informática na Educação (CBIE 2016)

Anais dos Workshops do V Congresso Brasileiro de Informática na Educação (CBIE 2016)

Umas das respostas mais surpreendentes e, ao mesmo tempo, uma das mais importantes foi a de número 4, em que foram interrogados se conseguiriam digitar um texto com os dedos no local correto do teclado, $100 \%$ da turma responderam Sim. Nesta pergunta, pode-se constatar o quanto o curso beneficiou o público atendido, uma vez que eles não possuíam tal habilidade antes da execução do projeto. Vale frisar que o teclado utilizado para o projeto foi o teclado alfanumérico normal, pois o objetivo da idealizadora do projeto era que os DVs conseguissem digitar em teclados sem nenhuma adaptação, isso para que eles tivessem êxito em digitar qualquer conteúdo dentro e fora do laboratório de informática, pois sabe-se que existe poucas repartições que possuem teclados adaptas para os Deficientes Visuais. Veja o gráfico 1.

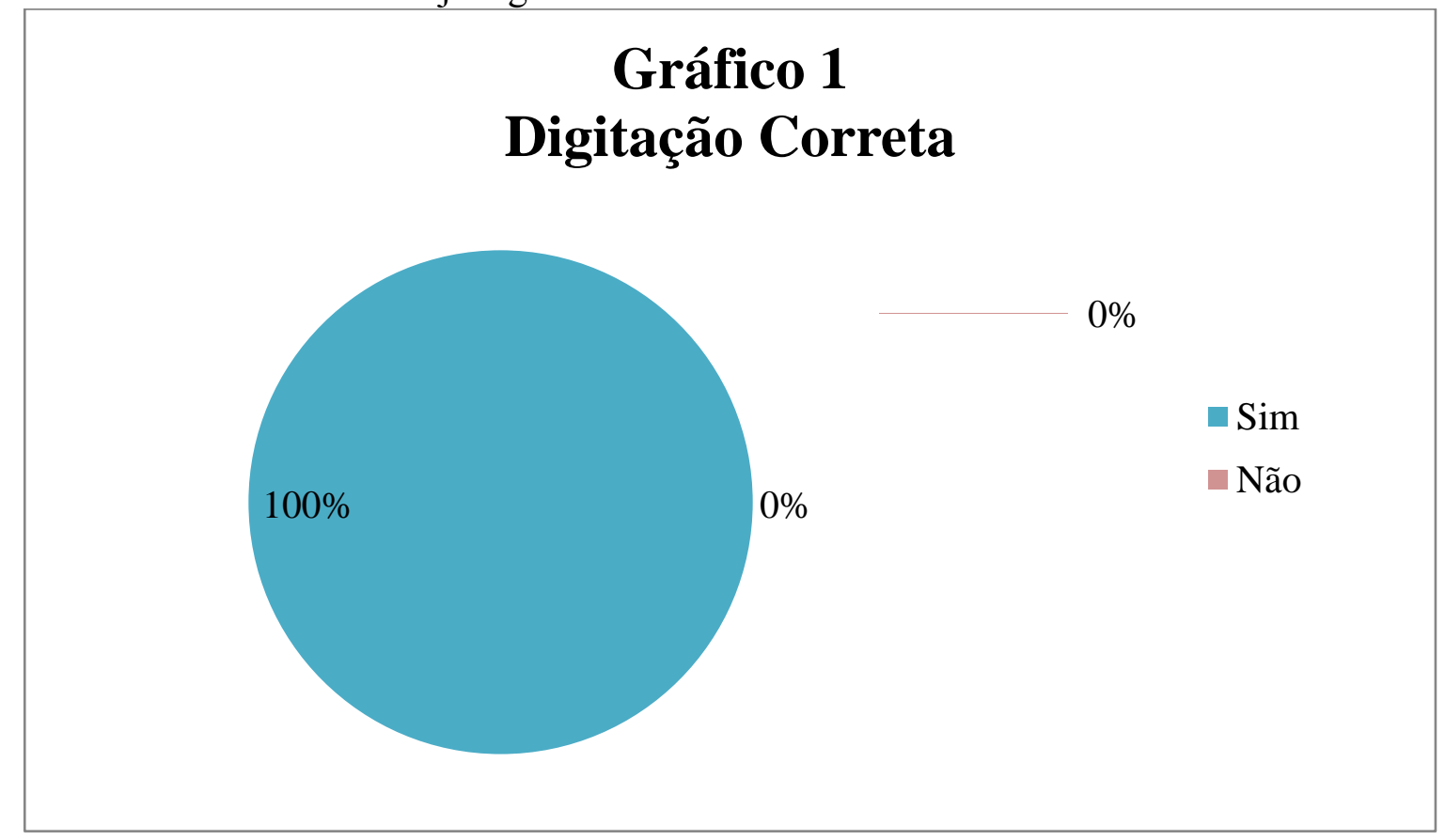

Gráfico 1: Alunos que conseguem digitar um texto com dedos no local correto do teclado.

Fonte: Questionários aplicados.

Todos os alunos concordaram que para se aprender o sistema DosVox exige muita paciência e força de vontade. Tal afirmação comprova o quanto os DVs são dotados de boa vontade e persistência, uma vez que manusear um computador sem o auxílio da visão não é uma tarefa tão fácil, porém possível.

Com relação à carga horária de 52 (cinquenta e duas) horas aulas de curso, 71,4\% dos alunos assinalaram que é possível aprender muitas coisas, mas a carga horária ainda é insuficiente; $14,3 \%$ acreditam que essa carga horária não é suficiente para aprender o DosVox e o mesmo percentual pondera que é possível Sim.

Questionados sobre a localização da maioria das teclas do teclado, sair e entrar no DosVox, digitar, salvar, localizar e palavras texto, localizar utilitários, digitar por meio do DosVox, 100\% dos alunos alegaram que sabem realizar todos os comandos descriminados, o que comprova a eficácia do projeto para a vida dos alunos assistidos, pois por meio dos comandos descriminados o usuário pode podem realizar inúmeras tarefas. $\mathrm{O}$ gráfico 2 demonstra o resultado. 


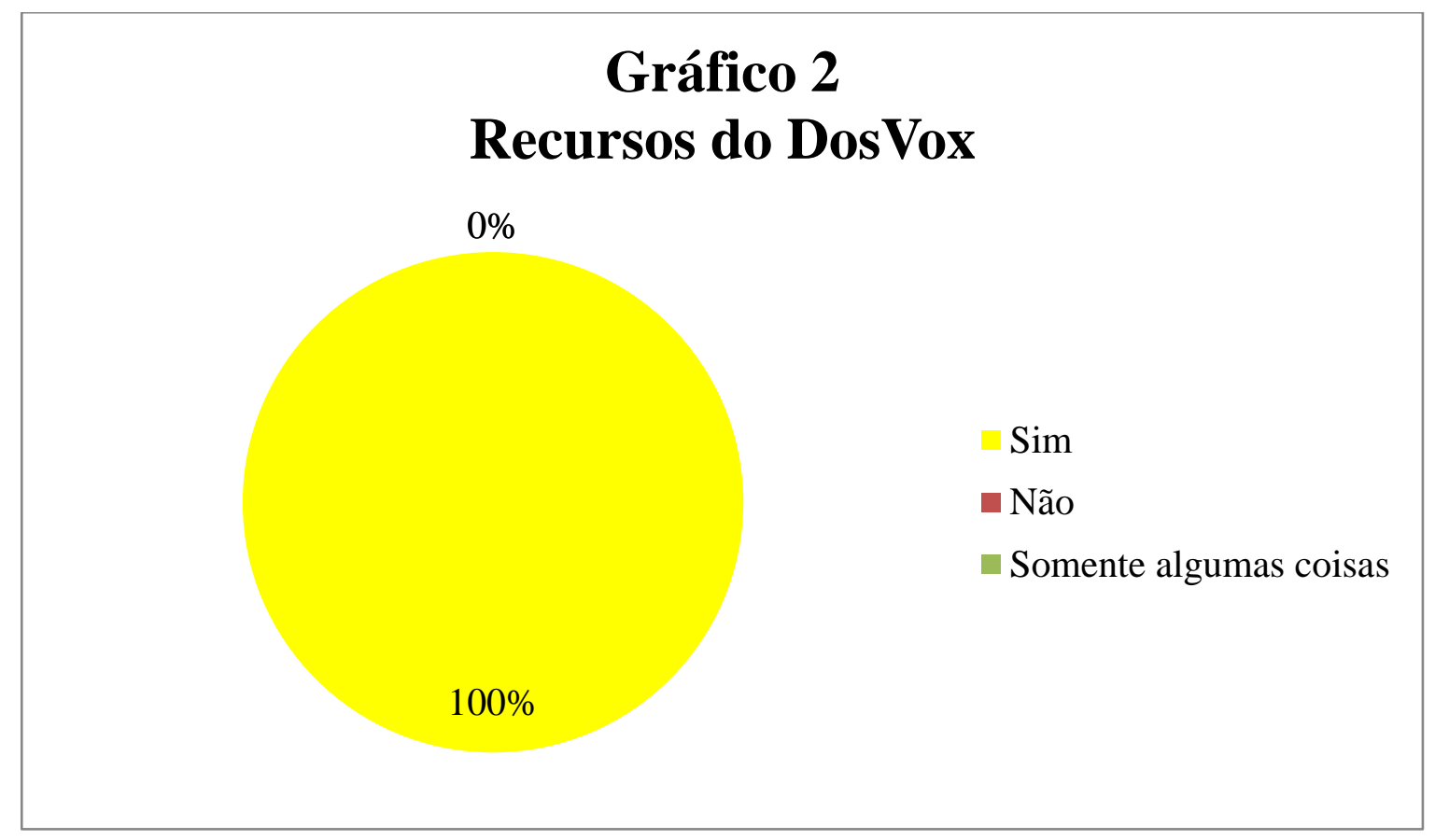

Gráfico 2: Alunos que sabem localizar maioria das teclas do teclado, sair e entrar no DosVox, digitar, salvar, localizar palavras e textos, localizar utilitários.

Fonte: Questionários aplicados.

Os dados apontam que 100\% dos Deficientes Visuais acreditam que o Software utilizado no projeto pode diminuir as barreiras existentes entre a tecnologia e os DVs. Para ratificar, Rodrigues (2010, p.45) declara que o "Sistema DosVox é usado por pessoas com deficiência visual para se ter acesso ao computador, além de ter muitas possibilidades de trabalhar com textos e pode ser descrito sob o ponto de vista tanto dos videntes e não videntes", ou seja, o programa foi desenvolvido para que seja utilizado tanto por pessoas cegas quanto por pessoas videntes.

$\mathrm{O}$ antepenúltimo questionamento foi em relação ao teclado numérico do computador. Os DVs foram interrogados se conseguiriam localizar todos os números do teclado e se eles conseguiriam colocar os dedos na posição correta para usar o mesmo, todas as respostas foram Sim. A presente informação carrega consigo uma importância bem relevante para o resultado do projeto, uma vez que os DVs utilizam bastante o teclado numérico para realizar cálculos diversos. Durante o projeto foi percebível o interesse por tal assunto, pois os alunos constantemente queriam fazer uso da calculadora do computador. Analise o gráfico 3. 


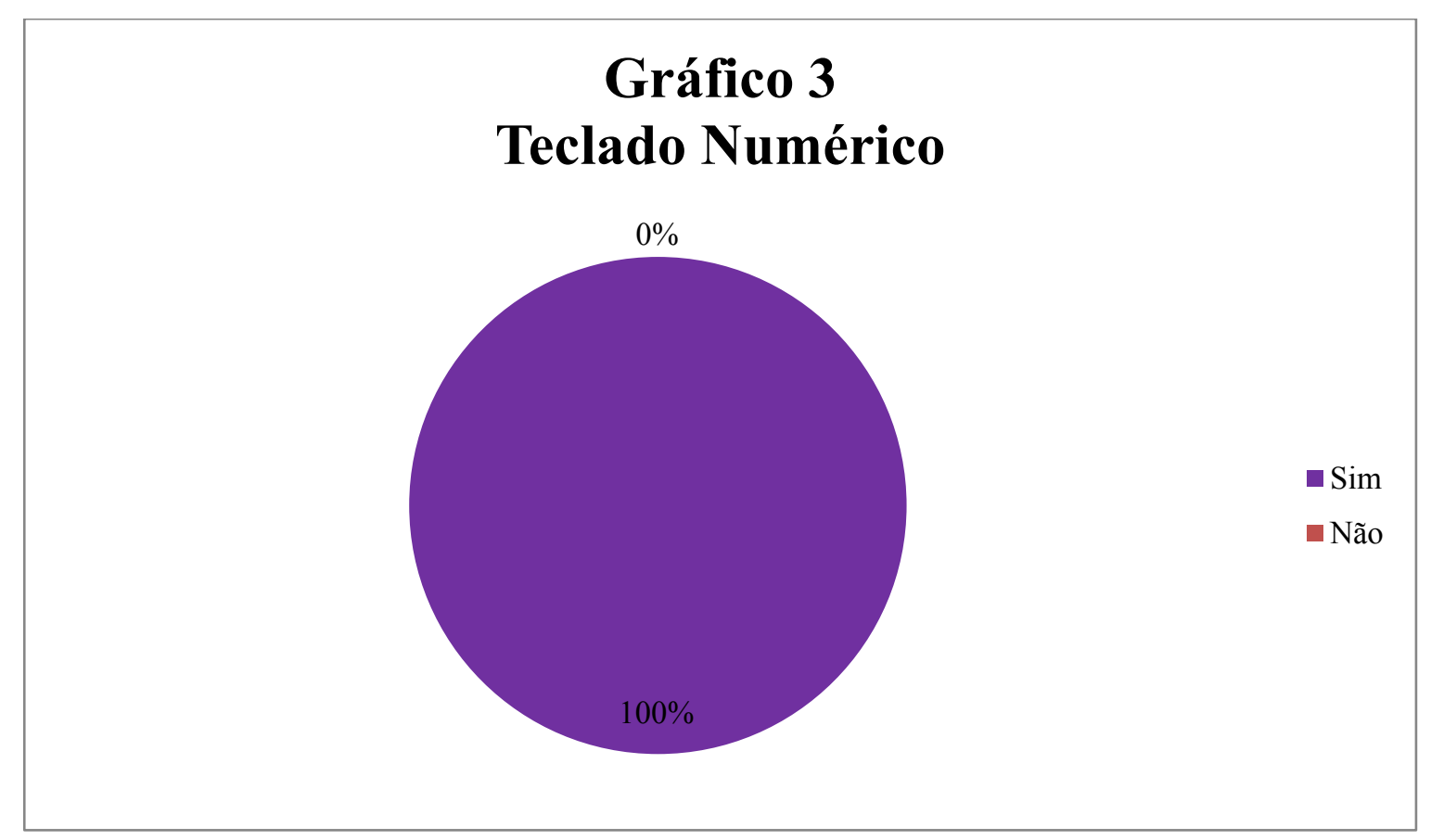

Gráfico 3: Alunos que conseguem localizar todos os números do teclado numérico

Fonte: Questionários aplicados.

O resultado a seguir demonstra a contribuição que o projeto pode trazer para o público beneficiado, pois apenas um aluno sabia ligar e desligar o computador, o restante da turma analisou que antes do projeto não sabia realizar tal atividade e ao final do projeto $100 \%$ da turma realizava a presente atividade de forma individual e sem auxilio das pessoas que estavam ao seu redor. Veja Gráfico 4.

\section{Gráfico 4 Ligar e desligar o computador}

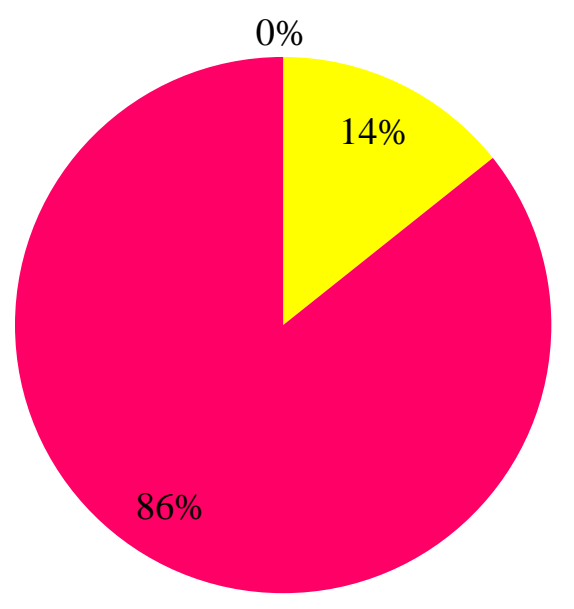

$\operatorname{Sim}$

— Não

- Somente o meu, mas de outras lugares ou pessoas não.

Gráfico 4: Alunos que sabiam ligar e desligar o computador antes do projeto.

Fonte: Questionários aplicados. 
Durante a realização do projeto os executores comprovaram o quanto a tecnologia pode ajudar, beneficiar os deficientes visuais e ajuda-los em sua autoestima uma vez que era constante a alegria durante o processo de aprendizagem, sobre o assunto Fernandes et al (2012) ratifica, que os recursos trazidos pela tecnologia foram fundamentais, e abriram novos paradigmas para as pessoas com deficiência, o que proporciona um espaço de permuta importante para o aumento da autoestima e da sensação de inclusão.

A última pergunta foi aberta, pois seria o momento dos alunos sugerirem melhorias para projetos futuros. Os alunos descreveram com bastante simplicidade suas sugestões: propondo que a carga horária mínima estivesse entre 100 a 120 horas; que ao final do curso os alunos pudessem realizar uma espécie de estágio, para colocar em prática os conhecimentos adquiridos; que o projeto disponibilizasse atividades em braile para os alunos; que houvesse uma continuidade do curso, ou seja, uma turma mais avançada e ambos estavam bem agradecidos pelo comprometimento que a instituição demonstrou sempre dando suporte as eventuais necessidades que ocorreram.

Segundo Mattar (1994), as principais vantagens das perguntas abertas é que as mesmas estimulam a cooperação dos respondentes, têm menor poder de influência nos participantes do que as perguntas com alternativas previamente estabelecidas e, acima de tudo, proporcionam comentários, explicações e esclarecimentos significativos. Suas desvantagens dizem respeito á difícil tabulação e análise e podem surgir dificuldades de entendimento como, por exemplo, letra ilegível, erro de redação, etc. As perguntas abertas foram de grande importância para o presente artigo, uma vez que elas servirão de subsídio para mediar o próximo projeto, que será executado pela idealizadora do trabalho.

Em suma, as sugestões registradas pelo público assistido foram analisadas e se fez de ponto-chave para o projeto futuro a ser desenvolvido, uma vez que os mesmo se mostraram bem solidários e parceiros em sala de aula, pois se tratava da primeira experiência da idealizadora do projeto e os DVs a todo momento procuravam sugerir melhorias para atividades futuras, a ideia do projeto foi recebida com muita alegria pelos alunos cegos, pois eles alegavam que dificilmente algum vidente propõe algo para que eles consigam desenvolver algo principalmente para seu lado computacional.

\section{Conclusões}

Destarte, é percebível que por meio do projeto executado houve uma construção do exercício da cidadania com a diminuição da exclusão social, através das parcerias firmadas com a instituição que apoiou o projeto, proporcionando às pessoas com deficiência visual contato direto com as tecnologias assistivas voltadas para sua deficiência, adquirindo conhecimento e domínio ao utilizar do sistema DosVox, pois o mesmo é um elemento facilitador para sua inclusão digital.

O projeto "Inclusão por meio do DosVox" incentivou e possibilitou os DVs fazerem uso das Tecnologias da Informação e Comunicação (TIC), tornando-os capazes de adquirir conhecimentos básicos e necessários para utilizar os recursos do computador, como digitar seus próprios textos, adquirir autonomia ao ligar e desligar o computador, fazer suas pesquisas na Internet, conhecer o teclado e realizar diversas atividades até melhor que muitos videntes.

\section{Referências}

ANDRADE, J M P de. (2002). Instituição: DEFNET Centro De Informática e informações sobre paralisias cerebrais Rio De Janeiro. In: III CONGRESSO IBEROAMERICANO DE INFORMÁTICA NA EDUCAÇÃO ESPECIAL - CIIEE 2002, 
V Congresso Brasileiro de Informática na Educação (CBIE 2016)

Anais dos Workshops do V Congresso Brasileiro de Informática na Educação (CBIE 2016)

Fortaleza.

Disponível

em:

http://www.niee.ufrgs.br/eventos/CIIEE/2002/programacao/Paineis.pdf. Acesso em: 23 de Março de 2016.

BORGES J A. (1998). DOSVOX: uma nova realidade educacional para deficientes visuais. Revista Benjamim Constant.

CERVO, A. L. BERVIAN, P. A. (2002). Metodologia científica. 5.ed. São Paulo: Prentice Hall,

FERNANDES, A. M; FERNANDES, A. P. S; COSTA, F.O.C; MOREIRA, D.S. (2012). Ensinando saúde bucal para deficientes visuais através de uma ferramenta web. In: WORKSHOP DE INFORMAV TICA NA EDUCAÇAW O (WIE), 18., 2012, Rio de Janeiro. Anais do 18o. Workshop de Informática na Educação (WIE), 2012. v. 1. p. 110.

GIL, A C. (2002). Técnicas de pesquisa em economia e elaboração de monografias. $4^{\text {a }}$ ed. São Paulo: Atlas.

MALHOTRA, N. (2001). Pesquisa de marketing. 3.ed. Porto Alegre: Bookman.

MATTAR, F. N. (1994) Pesquisa de marketing: metodologia, planejamento, execução e análise, 2a. ed. São Paulo: Atlas, 2v., v.2.

RODRIGUES, F S. (2010). O uso de Tecnologias da Informação e Comunicação (TIC) por alunos com deficiência visual em escola pública municipal de Fortaleza. / Francisco Sueudo Rodrigues. - Fortaleza: UFC, 2010. 125 f.: il. color. enc.; 21 x 29,7 $\mathrm{cm}$.

TAKAHASHI, T (Org.). (2000). Sociedade da informação no Brasil: livro verde. Brasília: Ministério da Ciência e Tecnologia, p. 45.

PANSANATO, L. T. E., SILVA, C. E. and RODRIGUES, L. (2012) "Uma Experiência de Inclusão de Estudante Cego na Educação Superior em Computação", in: XX Workshop sobre Educação em Computação. 